\title{
Dwarfs and Giants of Parathyroid Adenomas- No Difference in Outcome after Parathyroidectomy
}

\section{Abdel-Aziz $\mathrm{TE}^{1-3^{*}}$, Parameswaran $\mathbf{R}^{1}$, Gleeson $\mathrm{F}^{4}$, Sadler $\mathbf{G}^{1}$ and Mihai $\mathbf{R}^{1}$}

${ }^{1}$ Department of Endocrine Surgery, Churchill Cancer Centre, Oxford University Hospitals NHS Trust, Oxford, UK

${ }^{2}$ Department of Endocrine Surgery, University College London Hospital, NHS Trust, London, UK

${ }^{3}$ Department of Surgery, Alexandria University, Egypt

${ }^{4}$ Department of Radiology, Churchill Cancer Centre, Oxford University Hospitals NHS Trust, Oxford, UK

*Corresponding author: Abdel-Aziz TE, Department of Endocrine Surgery, Churchill Cancer Centre, Oxford University Hospitals NHS Trust, Oxford, UK, Tel: +420495833843; E-mail: t.abdel-aziz@ucl.ac.uk

Received date: December 22, 2017; Accepted date: January 12, 2018; Published date: January 16, 2018

Copyright: (C) 2018 Abdel-Aziz TE. This is an open-access article distributed under the terms of the Creative Commons Attribution License, which permits unrestricted use, distribution, and reproduction in any medium, provided the original author and source are credited.

\begin{abstract}
Objective: This study compares the outcome of parathyroidectomy for primary hyperparathyroidism (PHPT) in patients whose adenomas' weights were at the extremes of the distribution curve. As the size of parathyroid adenomas influences the success rate of localization studies for PHPT and negative localization can lead to higher risk of failed surgical treatment, it is possible that a difference in cure rate could be observed between subgroups of patients.
\end{abstract}

Study design: Case series

Methods: Data were retrieved from a prospective database maintained in a large University hospital.

Results: From a cohort of 519 patients who underwent parathyroidectomy for PHPT; two subgroups of patients were identified based on the extreme $10 \%$ of the distribution curve for adenomas' weight: adenomas $<300 \mathrm{mg}$ ("dwarfs", $\mathrm{n}=100$, median $200 \mathrm{mg}$ ) and $>3000 \mathrm{mg}$ ("giants", $\mathrm{n}=56$, median $4300 \mathrm{mg}$ ). Age was similar between groups. In comparison with giant adenomas, dwarf adenomas were associated with less severe hypercalcaemia (median 2.84 vs. $3.00 \mathrm{mmol} / \mathrm{l}, \mathrm{p}<0.001$ ) and lower PTH (median $11.7 \mathrm{vs.} 25.6 \mathrm{pmol} / \mathrm{l}, \mathrm{p}<0.001$ ). The occurrence of dwarf adenomas showed no trend during the study period $(23 / 173(13 \%)$ in $2000-2004$ vs. $36 / 217(17 \%)$ in 2007-2011).

Scan-directed parathyroidectomy was feasible in significantly more patients with giant adenomas (59\% vs. $38 \%)$. Persistent disease was diagnosed in three patients with dwarf adenomas and all were cured after a second operation. Patients with giant adenomas had no recurrence during a median follow-up of 25 months even though eight patients had histological features suggestive of atypical/malignant tumors.

Conclusion: Preoperative biochemistry is a poor predictor of adenomas' size even at the extremes of the distribution curve. Cure can be achieved in all patients with "dwarf" adenomas. Even in the presence of suspicious histological features, "giant" adenomas did not show malignant behavior.

Keywords: Primary hyperparathyroidism; Adenoma weight; Parathyroidectomy; Cure rate

\section{Introduction}

Primary hyperparathyroidism (PHPT) is a common endocrine disease with an incidence as high as 1 in 500 in postmenopausal women and a prevalence of up to $13 \%$ in those over 75 years old $[1,2]$. The severe symptoms suggested by the classical mnemonic of bonestones-abdominal moans-groans are rarely seen in Western practice and most patients are diagnosed when hypercalcaemia is moderate and symptoms might be considered to be absent [3]. Such patients are currently identified during screening for osteoporosis or on blood tests organized for unrelated complaints though many more might remain undiagnosed in the general population [4]. The current evidence-base for treating asymptomatic patients has been reviewed by the third NIH consensus but in current medical practice the endocrinologists might have a higher threshold for referral for surgical treatment and surgeons with large practice are unlikely to follow the restrictions suggested by the NIH consensus [5-7].

In the last decade the combination of $\mathrm{Tc}^{99 \mathrm{~m}}$-sestamibi scintigraphy and neck ultrasound has been used in most centers to select patients who would benefit from a scan-directed limited neck exploration, most commonly performed as an open minimally invasive parathyroidectomy (MIP) [8]. A cure rate of over $95 \%$ of MIP has been reported in numerous large series of patients operated with or without intraoperative PTH monitoring hence scan-directed parathyroidectomy has been widely adopted as the ideal treatment for PHPT [9]. As more patients are being identified earlier in the course of the disease it is expected that this could lead to the diagnosis of patients with smaller tumors. This hypothesis is based on the historical 
data showing a trend for increasing adenoma weight with increasing severity of hypercalcaemia.

If this assumption is true, it could be that small adenomas in patients with less severe hypercalcaemia might be more difficult to identify on preoperative localization studies (and possible less likely to be found during the operation); hence the risk of persistent or recurrent PHPT might be higher in such patients. The aim of this study is to compare the outcome of parathyroidectomy in patients with PHPT with tumors at the extremes of the distribution of their size.

\section{Methods}

A prospective database collected clinical, biochemical, pathological and follow-up data on consecutive patients operated for primary hyperparathyroidism. Patients with known familial disease and that undergoing redo parathyroidectomy were excluded from this analysis. All patients underwent preoperative localization studies using highresolution neck ultrasound and $\mathrm{Tc}^{99 \mathrm{~m}}$-sestamibi scintigraphy.

When both localization studies were positive and concordant, a scan-directed unilateral exploration was performed (minimally invasive parathyroidectomy, MIP). Bilateral neck exploration was performed in patients with discordant or negative scans.

As previously reported, intraoperative PTH was not used in any of the patients [10]. All operations were performed by one of the two Consultants (GS and RM) or a higher surgical trainee with a dedicated interest in endocrine surgery. Statistical analysis was performed using Excel-Windows (XLSTAT2011, Addinsoft, France).

Data with normal distribution are presented as mean \pm standard mean (range) are provided for data with non-normal distribution. Parametric and non-parametric tests were used accordingly. For all tests $p<0.05$ was considered significant.

\section{Results}

\section{Patients}

Between April 2000 and March 2011 a total of 662 patients underwent parathyroidectomy for PHPT. Patients with familial disease and renal hyperparathyroidism and those referred with persistent/ recurrent disease $(n=84)$ were excluded from analysis.
Patients with multi-gland disease and those with single adenomas whose weight was not recorded were also excluded $(n=59)$. Weight of parathyroid adenomas was available in 519 cases and these patients were included in further analysis. Demographic and biochemical details of those whose adenomas' weight was missing did not differ from those of the 519 include in analysis (data not shown).

The distribution of adenomas' weight was not normal (Shapiro-Wilk test). The lower and top 10 percentile were determined at 300 and 3000 mg. These values were used to identify two subgroups of patients: Those with "dwarfs" adenomas (weight $<300 \mathrm{mg}, \mathrm{n}=100$ ) and those with "giant" adenomas (weight $>3000 \mathrm{mg}, \mathrm{n}=56$ ). Age was similar between these two subgroups but the female predominance was more apparent in those with dwarf adenomas ( $88 \%$ vs. 65\%).

The occurrence of dwarf adenomas showed no significant trend during the study period as they were identified in $23 / 173(13 \%)$ patients in 2000-2004 vs. 36/217 (17\%) patients in 2007-2011 ( $\mathrm{p}=\mathrm{NS}$, chi-square test) (Figure 1) (Table 1).

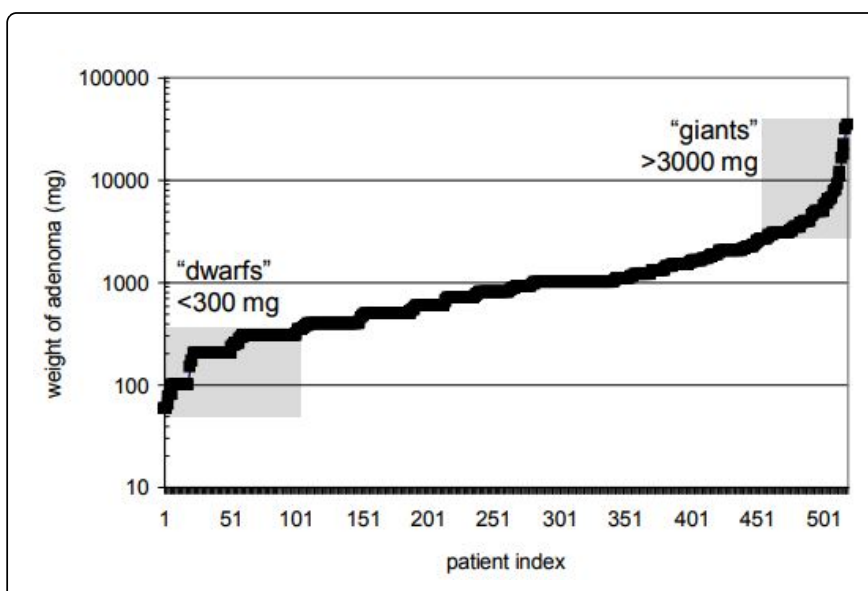

Figure 1: Distribution of weight of parathyroid adenomas in 519 patients with PHPT.

\begin{tabular}{|c|c|c|c|c|}
\hline Parameters & "dwarf"adenomas n=100 & $\begin{array}{l}\text { adenomas of "average" } \\
\text { weight } n=363\end{array}$ & "giant" adenomas $n=56$ & $\mathbf{p}^{*}$ \\
\hline Gender & $82 \mathrm{~F}: 18 \mathrm{M}$ & $266 \mathrm{~F}: 97 \mathrm{M}$ & $65(25-89)$ & $<0.01\left(\right.$ Chi $^{2}$ Test $)$ \\
\hline Age (years) & $69(24-89)$ & $63(17-90)$ & $65(25-89)$ & $p=n s$ \\
\hline Preop calcium (mmol/L) & $2.84(2.51-3.61)$ & $2.89(2.52-5.00)$ & $3.00(2.65-3.64)$ & $<0.001^{* *}$ \\
\hline Preop PTH (pmol/L) & $11.7(2.7-124.5)$ & $15.8(4.5-190)$ & $25.6(9.2-137)$ & $<0.001^{* *}$ \\
\hline Weight of adenomas (mg) & $200(60-300)$ & $990(310-2960)$ & $4300(3000-37000)$ & $<0.001^{* *}$ \\
\hline
\end{tabular}

Table 1: Comparison of preoperative parameters in patients found to have either "dwarf" or "giant" parathyroid adenomas. 
Citation: $\quad$ Abdel-Aziz TE, Parameswaran R, Gleeson F, Sadler G, Mihai R (2018) Dwarfs and Giants of Parathyroid Adenomas- No Difference in Outcome after Parathyroidectomy. J Steroids Horm Sci 9: 188. doi:10.4172/2157-7536.1000188

Page 3 of 5

\section{Biochemical, radiological and pathological characteristics}

There was only a weak correlation between the adenomas' size and the severity of hypercalcaemia (weight $=1716 \times[\mathrm{Ca}]-3421, \mathrm{R}^{2}=0.026$ ) and $\mathrm{PTH}$ values (weight $\left.=33 \times[\mathrm{PTH}]+824, \mathrm{R}^{2}=0.075\right)$ (Figure 2 ).
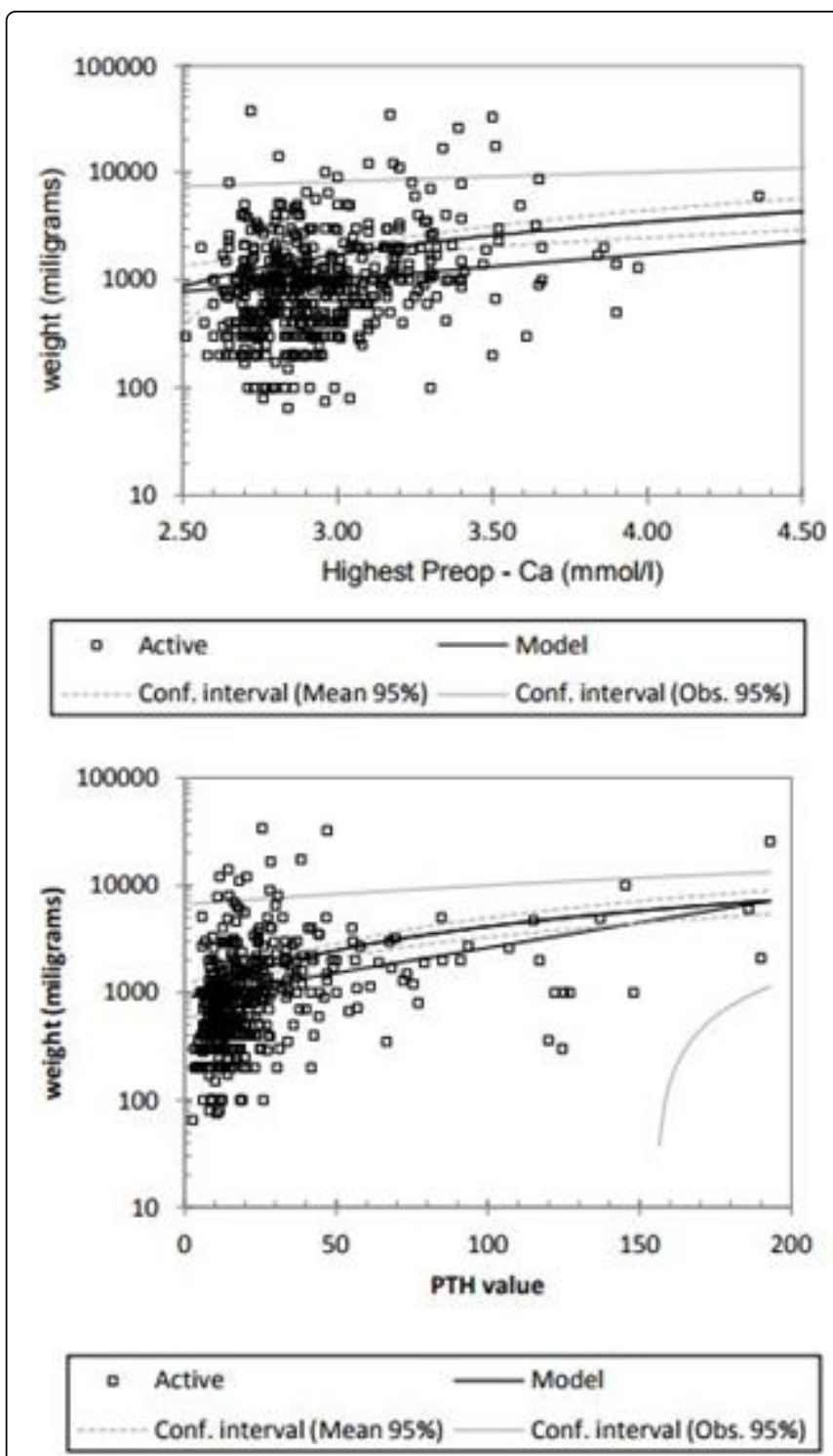

Figure 2: Correlation between highest preoperative calcium level (A) or PTH level (B) and the weight of the parathyroid adenomas.

Dwarf adenomas were associated with less severe hypercalcaemia and lower PTH when compared with "giant" adenomas (Table 1). With increasing severity of preoperative hypercalcaemia (from $<2.8$ to 2.8-3.0 or $>3.0 \mathrm{mmol} / \mathrm{L}$ ) there was an increase in the median weight of adenomas (530 vs. 800 vs. $1100 \mathrm{mg}, \mathrm{p}<0.0001$ Kruskal-Wallis test) with an increasing presence of "giant" adenomas (from 7\% to 19\%) and a decreasing incidence of dwarf adenomas (from 27\% to 6\%) (Figure 3).

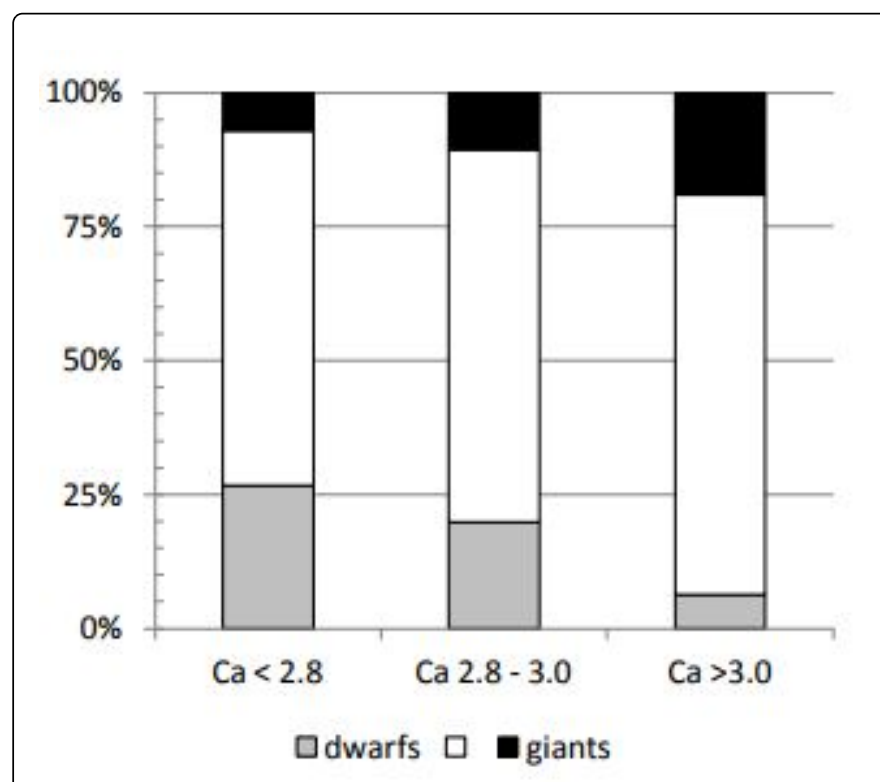

Figure 3: Incidence of "dwarf" and "giant" adenomas in subgroups of patients with varying severity of hypercalcaemia.

Positive preoperative localization was more likely in patients with "giant" adenomas compared with those with "dwarf" adenomas both for sestamibi (37/42(88\%) vs. 48/95(50\%)) and for ultrasound scanning $(38 / 50(76 \%)$ vs. $45 / 92(49 \%)$ (Fisher exact test in a $2 \times 2$ contingency table and two-tailed $\mathrm{p}<0.001)$.

Histological analysis of the adenomas demonstrated a predominance of chief cells in majority of adenomas in both subgroups (64/100 and 35/56, respectively, $p=N S$, chi-square test).

\section{Outcome of parathyroidectomy}

Scan-directed minimally invasive parathyroidectomy was feasible in $59 \%$ of patients with giant adenomas and $38 \%$ of "dwarf" adenomas. Majority of patients were discharged on the day of surgery and length of stay was similar for both groups (range 0-4 days, mode 0 ).

Persistent disease was diagnosed in three of 100 patients with dwarf adenomas. Subsequent reimaging demonstrated a second adenoma and at redo parathyroidectomy a larger adenoma was resected. During a follow-up of $39 \pm 27$ months (median 34 months) all patients have remained normocalcaemic $(2.30 \pm 0.61 \mathrm{mmol} / \mathrm{l})$.

Patients with giant adenomas had no recurrence during a median follow-up of 25 months (average $34 \pm 26$ months) even though eight patients had tumors with histological features suggestive of atypical/ malignant tumors (Figure 4). 


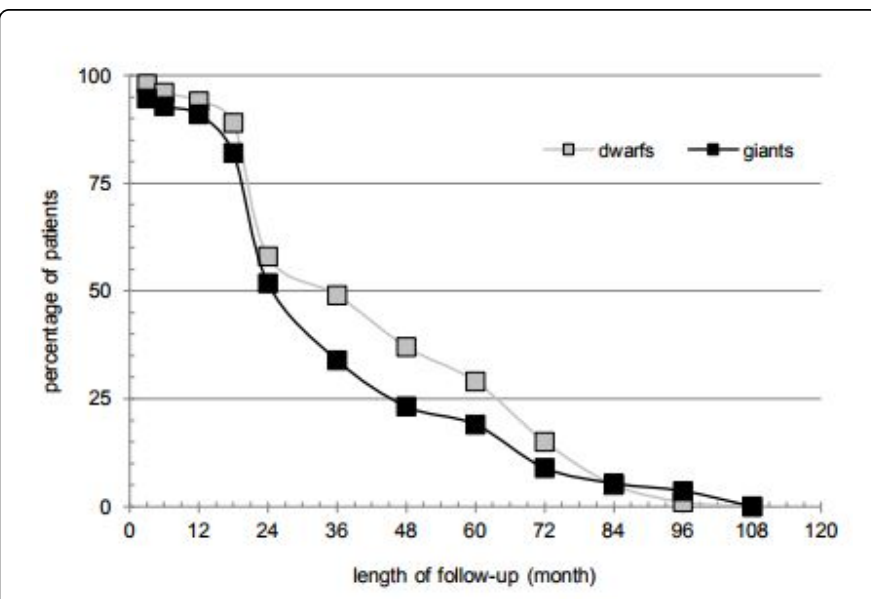

Figure 4: Monthly follow-up after parathyroidectomy.

\section{Discussion}

This study is based on the analysis of a cohort of over 500 patients with primary hyperparathyroidism (PHPT) operated over a decade in a University center and reports excellent cure rates of parathyroidectomy independent on the size of parathyroid adenomas.

Parathyroidectomy for PHPT is an increasingly common operation as the disease incidence is increasing in an aging population. In addition to large personal series, national registries from Sweden and the United Kingdom reported cure rates in excess of $95 \%$ parathyroidectomy [11]. Such multicenter data collection also showed that only two thirds of patients have localization studies and that the subgroup of patients with negative localization studies might have a much higher risk (up to 20\%) of unsuccessful operation [12]. As size of the adenomas is one of the factors potentially influencing the success of localization studies, we compared the outcome of parathyroidectomy in patients with adenomas whose weight was at the extremes of the distribution curve.

The correlation between the severity of biochemical abnormalities and size of parathyroid adenomas has long been debated [13-16]. Despite the fact that dwarf adenomas were more likely in patients with calcium $<2.8 \mathrm{mmol} / \mathrm{L}$ than in those with $\mathrm{Ca}>3 \mathrm{mmol} / \mathrm{L}$, preoperative biochemical parameters would not have predicted the likelihood of encountering a "dwarf" or a "giant" adenoma. It can be suggested however that in a patient with severe hypercalcaemia $(>3.0 \mathrm{mmol} / \mathrm{l})$ and negative scans the finding of a minimally enlarged gland should prompt further exploration for identification of a possibly much larger ectopic gland either in the anterior mediastinum or the posterior mediastinum (acquired ectopia of a "giant" superior adenomas sliding along the prevertebral fascia in a paraoesophageal position). Similarly, in a patient with minimal hypercalcaemia the finding and the excision of a slightly enlarged gland might be sufficient treatment and one should not extend the exploration. A similar protocol was suggested by the authors of the "Wisconsin index" in which the product between calcium and PTH concentration can be trace on a nomogram that allows one to estimate the risk of multigland disease [17]. Based on their data for example, for a Wisconsin index of less than 800 and a gland weight of $500 \mathrm{mg}$; there is a $9 \%$ chance for additional hyper functioning parathyroid glands but if the WIN is 801 to 1600 these chances increase to $28 \%$, and if the WIN is more than 1600 the chance of multi gland disease is $61 \%$ [17].

During the period analyzed there was no significant change in the incidence of "dwarf" adenomas. This finding doesn't support the hypothesis that the current more proactive approach for diagnosing patients with PHPT is not identifying patients at an earlier stage of their disease. It is of historical interest to note that in Fuller Albright's first report of parathyroidectomy in 1940s in eight patients with severe symptoms the adenomas weight was in excess of $11 \mathrm{gm}$. In contrast, in our series of over 600 patients only seven patients had tumors with weights in excess of $11 \mathrm{gm}$ and half of patients had tumors $<1$ gram.

For small parathyroid adenomas the main concern remains the limitation of current localization studies to demonstrate the position of such tumors. Several studies have shown that sestamibi is less sensitive for smaller adenomas and that on neck ultrasonography such tumors cannot be easily differentiated from thyroid nodules or local lymph nodes [8]. Confirming these previously reported data in our series scan-directed parathyroidectomy was less likely in patients whose adenomas were $<300 \mathrm{mg}$. Never the less, such small adenomas could be identified intraoperatively through a systematic neck exploration by comparing their appearance/size with that of the other (three) normal glands.

Though large adenomas are readily demonstrated on ultrasound, some do not uptake the radioactive tracer hence sestamibi scintigraphy was found to be negative in $12 \%$ of patients with giant adenomas. The preoperative description of a large parathyroid tumor should raise suspicion of a parathyroid carcinoma and such patients might need a simultaneous ipsilateral thyroid lobectomy. In our practice, the decision to perform a lobectomy was taken in only five patients with macroscopic suspicion of locally-invasive tumor. For cases where the "giant" parathyroid adenoma was easily dissected off the surrounding structures, no thyroid lobectomy was performed. Despite such a "conservative" approach there have been no cases of local or distant recurrence. Such decisions could be facilitated by the introduction in routine clinical practice of histological analysis currently available only in research settings such as demonstrating the loss of expression of parafibromin in parathyroid carcinomas [18-20].

In summary, size of parathyroid adenomas has no impact on the cure rate of parathyroidectomy for primary hyperparathyroidism. Small adenomas missed on preoperative localization studies can be identified reliably during bilateral neck exploration. At the opposite extreme, giant adenomas are seldom malignant and local excision is sufficient for the vast majority of them.

\section{Author Contributions}

All authors contributed to the collection/analysis of data and writing of the manuscript.

\section{References}

1. Adami S, Marcocci C, Gatti D (2002) Epidemiology of primary hyperparathyroidism in Europe. J Bone Miner Res 17: N18-N23.

2. Wermers RA, Khosla S, Atkinson EJ, Hodgson SF, O'Fallon WM, et al. (1997) The rise and fall of primary hyperparathyroidism: A populationbased study in Rochester, Minnesota, 1965-1992. Ann Intern Med 126: 433-440.

3. Mihai R, Wass JA, Sadler GP (2008) Asymptomatic hyperparathyroidismNeed for multicentre studies. Clin Endocrinol (Oxf) 68: 155-164. 
Citation: $\quad$ Abdel-Aziz TE, Parameswaran R, Gleeson F, Sadler G, Mihai R (2018) Dwarfs and Giants of Parathyroid Adenomas- No Difference in

Page 5 of 5

4. Yu N, Donnan PT, Murphy MJ, Leese GP (2009) Epidemiology of primary hyperparathyroidism in Tayside, Scotland, UK. Clin Endocrinol (Oxf) 71: 485-493.

5. Bilezikian JP, Khan AA, Potts JT Jr. (2009) Guidelines for the management of asymptomatic primary hyperparathyroidism: Summary statement from the third international workshop. J Clin Endocrinol Metab 94: 335-339.

6. Mahadevia PJ, Sosa JA, Levine MA, Zeiger MA, Powe NR (2003) Clinical management of primary hyperparathyroidism and thresholds for surgical referral: A national study examining concordance between practice patterns and consensus panel recommendations. Endocr Pract 9: 494-503.

7. Kouvaraki MA, Greer M, Sharma S, Beery D, Armand R, et al. (2006) Indications for operative intervention in patients with asymptomatic primary hyperparathyroidism: Practice patterns of endocrine surgery. Surgery 139: 527-534.

8. Mihai R, Simon D, Hellman P (2009) Imaging for primary hyperparathyroidism-An evidence-based analysis. Langenbecks Arch Surg 394: 765-784.

9. Bergenfelz AO, Hellman P, Harrison B, Sitges-Serra A, Dralle H (2009) Positional statement of the european society of endocrine surgeons (ESES) on modern techniques in pHPT surgery. Langenbecks Arch Surg 394: 761-764.

10. Mihai R, Palazzo FF, Gleeson FV, Sadler GP (2007) Minimally invasive parathyroidectomy without intraoperative parathyroid hormone monitoring in patients with primary hyperparathyroidism. Br J Surg 94: 42-47.

11. Bergenfelz A, Jansson S, Martensson H, Reihner E, Wallin G, et al. (2007) Scandinavian quality register for thyroid and parathyroid surgery: Audit of surgery for primary hyperparathyroidism. Langenbecks Arch Surg 392: 445-451.

12. Bergenfelz AO, Wallin G, Jansson S, Eriksson H, Martensson H, et al. (2011) Results of surgery for sporadic primary hyperparathyroidism in patients with preoperatively negative sestamibi scintigraphy and ultrasound. Langenbecks Arch Surg 396: 83-90.

13. Randhawa PS, Mace AD, Nouraei SA, Stearns MP (2007) Primary hyperparathyroidism: Do perioperative biochemical variables correlate with parathyroid adenoma weight or volume. Clin Otolaryngol 32: 179-184.

14. Mozes G, Curlee KJ, Rowland CM, van Heerden JA, Thompson GB, et al. (2002) The predictive value of laboratory findings in patients with primary hyperparathyroidism. J Am Coll Surg 194: 126-130.

15. Bindlish V, Freeman JL, Witterick IJ, Asa SL (2002) Correlation of biochemical parameters with single parathyroid adenoma weight and volume. Head Neck 24: 1000-1003.

16. Hamidi S, Aslani A, Nakhjavani M, Pajouhi M, Hedayat A, et al. (2006) Are biochemical values predictive of adenoma's weight in primary hyperparathyroidism? ANZ J Surg 76: 882-885.

17. Mazeh H, Chen H, Leverson G, Sippel RS (2013) Creation of a "wisconsin index" nomogram to predict the likelihood of additional hyperfunctioning parathyroid glands during parathyroidectomy. Ann Surg 257: 138-141.

18. Cetani F, Pardi E, Ambrogini E, Banti C, Viacava P, et al. (2008) Hyperparathyroidism 2 gene (HRPT2, CDC73) and parafibromin studies in two patients with primary hyperparathyroidism and uncertain pathological assessment. J Endocrinol Invest 31: 900-904.

19. Gill AJ, Clarkson A, Gimm O, Keil J, Dralle H, et al. (2006) Loss of nuclear expression of parafibromin distinguishes parathyroid carcinomas and hyperparathyroidism-jaw tumor (HPT-JT) syndrome-related adenomas from sporadic parathyroid adenomas and hyperplasias. Am J Surg Pathol 30: 1140-1149.

20. Tan MH, Morrison C, Wang P, Yang X, Haven CJ, et al. (2004) Loss of parafibromin immunoreactivity is a distinguishing feature of parathyroid carcinoma. Clin Cancer Res 10: 6629-6637. 